\title{
Supporting People Experiencing a Burn Injury to Return to Work or Meaningful Activity: Qualitative Systematic Review and Thematic Synthesis
}

Jessica van Bentum BHSC (Physiotherapy)

Centre for Person Centred Research, Auckland University of Technology, Auckland, New Zealand

Julia Nicholson BHSC (Physiotherapy)

Centre for Person Centred Research, Auckland University of Technology, Auckland, New Zealand

Natasha Bale PGCert (Health Science), BHSC (Physiotherapy)

Waikato Burns Unit, Waikato District Health Board, Hamilton, New Zealand

Joanna K. Fadyl PhD, MSc, BSc (Psychology)

Centre for Person Centred Research, Auckland University of Technology, Auckland, New Zealand

\section{ABSTRACT}

Qualitative studies contain in-depth information about facilitators and barriers to successful rehabilitation. This systematic review synthesised findings across qualitative studies to inform vocational rehabilitation practices for people who have experienced burn injury. PRISMA guidelines were used to determine inclusion criteria for the review and develop a comprehensive search strategy. Four databases were searched and results screened. Included studies investigated experiences of return to work (RTW) or meaningful activity in a burn injury population. Quality of included articles was examined using the CASP framework for qualitative research Thematic synthesis was used to analyse the qualitative results. Six studies met inclusion criteria. Five analytic themes were identified regarding experiences of vocational support and ability to RTW after burn injury: addressing the complex impact of burn injury; personal connections as vital support; skilled and specialised healthcare as central to RTW; value of knowledge; and considering the work environment. No included studies investigated meaningful activity other than paid work. Findings support structured vocational rehabilitation, psychological interventions, social support, intensive rehabilitation and patient, clinician and workplace education as key in facilitating RTW after burn injury. Additionally, coordinated care is likely to improve vocational outcomes. Research is needed on supporting return to meaningful activity.

Van Bentum, J., Nicholson, J., Bale, N. \& Fadyl, J. K. (2021). Supporting people experiencing a burn injury to return to work or meaningful activity: Qualitative systematic review and thematic synthesis. New Zealand Journal of Physiotherapy, 49(3), 134-146. https://doi.org/10.15619/NZJP/49.3.04

Key Words: Burns, Qualitative research, Rehabilitation, Systematic Review, Vocational

\section{INTRODUCTION}

Survival rates following burn injury have notably improved worldwide due to medical and surgical advances (Espinoza et al., 2019). Quality of life following burn care is now the focus of most burns research (Espinoza et al., 2019). Return to work (RTW) is a key rehabilitation goal and is identified as a valid indicator of post-burn injury physical and psychosocial health (Espinoza et al., 2019). RTW is defined here as engaging in work in any capacity after health-related impairment. Achievement of RTW or meaningful activity helps people who have experienced burn injury regain a sense of normality and is an indicator of community reintegration (Johnson et al., 2016; Mason et al., 2012).

The Burn Registry of Australia and New Zealand (BRANZ) recorded 437 admissions to Aotearoa New Zealand inpatient burns units between 2018 and 2019 (Tracy et al., 2020). Scald, contact and flame burns remain the most common mechanism of injury and the vast majority of injuries happen in the person's own home (Tracy et al., 2020). The trend of severity of burn injuries remains stable, with the majority of injuries being less than 10\% total body surface area (TBSA) (Tracy et al., 2020). In New Zealand, the current criteria for a person who has experienced an acute burn injury to attend a regional burn unit includes, but is not limited to, a TBSA greater than 10\% in an adult or $5 \%$ in a child, burns to specific areas such as face, hands or perineum, electrical or chemical burns, or burns with inhalation injuries (Counties Manukau Health, 2021). The current criteria for admission to the national burn unit includes, but is not limited to, burns greater than 30\% TBSA, full thickness burns to face, hands, genatalia or perineum, significant inhalation injury, and significant electrical or chemical burns. Specialised burn-experienced physiotherapists are part of the treating multidisciplinary team (MDT) at the national burns unit and the regional burn units. The rehabilitation pathway may differ between individuals, depending on the severity and mechanism of the injury, patient demographics and existing co-morbidities, resources available at their hospital of admission, and support provided by the Accident Compensation Corporation (ACC). ACC guidelines state that burn injury rehabilitation must be carried out in a designated District Health Board (DHB) facility but do not provide specific rehabilitation 
processes, therefore permitting the treating therapist to provide rehabilitation and RTW strategies at their discretion (Accident Compensation Corporation, 2016).

A 2012 systematic review by Mason and colleagues estimated that $28 \%$ of individuals experiencing burn injury never RTW. Although New Zealand statistics were not included in this review, it is reasonable to infer that New Zealand burns patients face similar challenges to what is reported in this review (Mason et al., 2012). In New Zealand, 99\% of burns patients' healthrelated costs are funded by ACC, which is a no-fault personal insurance scheme for accidental injuries (Tracy et al., 2019). ACC funds medical costs, post-discharge support and also vocational rehabilitation and $80 \%$ wage compensation. Wage compensation and vocational rehabilitation continues until the person is work-able, determined by a RTW or an assessment that the person could work in a suitable job according to both medical and vocational criteria (New Zealand Accident Compensation Act, 2001). According to ACC statistics, weekly wage compensation costs for people with burn injuries between 2018 and 2019 were \$5,315,779 (personal communication, April 6, 2020). Therefore, burn injuries pose not only significant healthcare costs, but delayed RTW following injury also creates an additional economic load due to productivity loss and compensation claims.

Returning to work requires people with burn injury to overcome persistent injury-related challenges including tissue contractures, pain, weakness, psychological issues, scarring and insecurities over altered physical appearances (Mason et al., 2012). A 2010 systematic review reported time to RTW following burn injury in the USA, China, Australia and Sweden as ranging from 4.7 weeks to two years (Quinn et al., 2010). This research illustrates the variable and often lengthy RTW experience. Vocational rehabilitation (VR) employs a MDT approach aimed at optimising RTW among individuals experiencing a healthrelated impairment (Escorpizo et al., 2011). In New Zealand, physiotherapists are involved in VR for people with burn injury both in early intervention as staff on burns units and as specialised VR providers. This often involves teamwork among occupational therapists, VR counsellors, psychologists, social workers, case-managers and medical staff (Esselman, 2011; Gobelet et al., 2007). Physiotherapy contribution is crucial; therefore, research in this field is significant to physiotherapy practice. However, with limited research on effective practices specifically in relation to $V R$, it can be challenging for physiotherapists to decide on best use of time and resources. Comprehensive VR programmes are individualised and include interventions like vocational training, guidance, education, goal setting, job placement and vocational counselling (Gobelet et al., 2007). Successful VR has obvious benefits for people with burn injury while generating positive social and economic effects through the prevention of long-term sickness and disability (Waddell et al., 2008).

Despite the importance of social and work reintegration following burn injury, there is limited literature or guidelines detailing intervention protocols that facilitate RTW. Therefore, supports likely differ between burns units. Additionally, the clinical trial evidence in this area is still extremely limited. Our search identified only one randomised controlled trial published since 2005 that specifically investigated RTW after burn injury (Wiechman et al., 2015). This study, conducted in the USA, compared an expanded delivery model of burn care to standardised outpatient care, and there were some concerns about risk of bias. At present, the most productive avenue is to examine experiences reported in the qualitative literature to identify promising interventions for further testing. The authors aimed to address this need through a systematic review of qualitative literature related to supporting RTW or meaningful activity after burn injury. Meaningful activity was defined as any physical, social or leisure activities important to a person.

Qualitative studies are designed to explore complex lived experiences and social processes, and therefore they are specific to the context in which they were conducted. When multiple qualitative studies are synthesised, it is possible to retain the nuanced understanding of a phenomenon that is enabled by qualitative research, while generating insights that cut across the different study contexts (Flemming et al., 2019). This type of review can also be used to identify possible interventions for future testing (Levack, 2012). There are several methods of conducting synthesis of qualitative studies. For this study, we selected thematic synthesis (Thomas \& Harden, 2008) based on guidelines published in the Cochrane handbook for systematic reviews of interventions (Higgins et al., 2019) - an approach appropriate for the type of research question, and capable of producing well-developed themes.

\section{METHODS}

The research question this review addressed was: What does qualitative research evidence indicate is useful to support an individual experiencing burn injury to RTW or meaningful activity?

Definition of terms for database search and screening for inclusion

We employed a pre-planned database search strategy across four databases, specifying keywords and subject terms adapted for each database. The key definitions that structured our search are outlined below. Specific keywords used are presented in Table 1.

\section{Table 1}

Search Terms

\begin{tabular}{ll}
\hline Population & "burn* patient* " OR "burn* injur* " OR \\
terms & "burn* rehabilitat* " OR "burn* model* " OR \\
& "burn* care" OR "burn* survivor* " \\
Intervention & "return to work" OR "rtw" OR "return to \\
terms & employment" OR employment OR "work \\
& reintegration" OR "work re-entry" OR "work \\
& resumption" OR "vocational rehabilitat*" \\
& OR "meaningful activit* " OR "meaningful \\
& occupation*" \\
\hline
\end{tabular}

Note. Population and intervention terms were combined in the search with AND.

\section{Included populations}

The review included studies where participants were 16 years of age or older, who had experienced burn injury. A burn injury 
was defined according to the BRANZ definition, encompassing contact with hot objects, hot liquids or steam, chemicals, electrical current, fire or flame, radiation, radiant heat, flashes of energy produced by explosive material or friction-type movement of a surface against the skin (Tracy et al., 2019).

\section{Included interventions and related outcomes} Included interventions involved any type of support aiming to assist people who have experienced burn injury to remain in or RTW or meaningful activity. Studies were excluded if there was a lack of discussion of or focus on RTW or meaningful activity. RTW was defined as engaging in work in any capacity after health-related impairment and return to meaningful activity was defined as engaging in any physical, social or leisure activities important to that person

\section{Included study designs}

All qualitative study designs except qualitative systematic reviews were considered eligible for inclusion. Relevant study designs included, but were not limited to, grounded theory, qualitative descriptive, ethnography, critical, post-structural or Indigenous methodologies. Other qualitative systematic reviews including evidence synthesis were excluded due to potential double-up of study data with original studies.

Timeframe

A 15-year search timeframe was chosen for study eligibility to ensure appropriate relevancy accounting for changes in job market conditions and policy environments over that time.

Sources of research reports

We searched four databases in February 2020 for peer reviewed articles published between 1 January 2005 and 27 February 2020. The databases were CINAHL, MEDLINE, SPORTDiscuss and Scopus. We also conducted a manual search of reference lists of included articles.

\section{Study quality}

As thematic synthesis synthesises the findings across studies, it was important that all data included for synthesis was considered trustworthy. To this end, studies included for data extraction were required to meet critical methodological quality criteria. These criteria were appropriate methodology, design and data collection, and sufficiently rigorous analysis, including a clear statement of findings - each mapping onto a specific question in the critical appraisal tool (see below).

\section{Study screening}

The team involved in study screening and subsequent quality assessment included two final-year trainee physiotherapists (JvB, $J N)$, a senior burns physiotherapist (NB), and an experienced qualitative researcher with expertise in both qualitative synthesis and vocational rehabilitation (JF). Initially, two review authors $(J \vee B, J N)$ independently considered the titles and abstracts from the studies identified and screened for relevance to the research questions. All studies that had any possibility of meeting inclusion criteria for topic and population at title and abstract screening were included for full text screening, and methodology/study type was not screened until full text stage. The same two authors conducted full text screening, also independently before discussing consensus. Disagreement or uncertainty about relevance for inclusion was discussed with the senior author, and involved consideration of full study reports. The screening process was managed using Rayyan software (Ouzzani et al., 2016).

\section{Quality assessment}

Two review authors (JvB, JN) independently assessed for methodological quality using the Critical Appraisal Skills Programme qualitative checklist (Public Health Resource Unit, 2002). Section A (six items) assesses the study design as it affects validity of results. Section B (three items) addresses the reporting of results directly. Section $C$ addresses external validity. As with screening, uncertainties and disagreements were discussed with the senior author and resolved by consensus. Each item was scored 'yes', 'no' or 'can't tell'. Where an item scored 'can't tell' and it was critical to our inclusion criteria for quality (see quality inclusion criteria above), study authors were contacted for clarification.

\section{Data extraction}

Two authors (JvB, JN) independently extracted key information from all included studies including full citation, authors, year published, country, sample size, methodology (such as grounded theory), intervention (where relevant) and study findings. Extracted data was compared and any disagreements were handled in the same way as for screening and quality assessment. The data for analysis for each study was the extracted text from the 'results' or 'findings' and 'discussion' sections.

\section{Thematic synthesis}

Included qualitative data was synthesised using methods of thematic synthesis outlined by Thomas and Harden (2008). Thematic synthesis is an established method used to inform practice recommendations through development of analytic themes, which presents data in an accessible form. This method was selected as it meets the review's objective of identifying patterns within existing qualitative literature to make informed conclusions.

The first stage involved two authors (JN, JvB) independently coding the results, quotations and discussions of each study, line by line, according to meaning and context. Codes were placed into Google Docs for cross-review. Codes were checked alongside the original text to confirm consistency of interpretation and to identify whether additional levels of coding were required (Thomas \& Harden, 2008)

The second stage involved identifying similarities and differences between codes to develop descriptive themes that capture and describe patterns in the data (Thomas \& Harden, 2008). Codes with the same meaning were combined into new codes. All codes were then placed into Miro (www.miro.com), an online whiteboard. Similar codes were arranged together into hierarchical tree structures. From this, the study team developed five descriptive themes.

The final stage involved generating analytic themes that expanded beyond the original data and addressed the review question. The team discussed each theme with the aim of describing an overarching meaning in the context of inferences for appropriate support. At this stage, ideas became more abstract and analytic themes superseded the prior descriptive 
themes. Both the in-depth knowledge of the descriptive themes from the prior work and the depth of experience within the research team in relation to burns rehabilitation and vocational rehabilitation were crucial to this stage of analysis. Results presented below are the result of the analytic theme stage of analysis. That is, they go beyond the findings of the original study into interpretation only possible with synthesis of multiple studies. Where reported results related to specific studies, these are referenced. Where the interpretation is a synthesis that goes beyond this, we have not referenced original studies.

\section{RESULTS}

\section{Search results}

Figure 1 shows the screening outcomes. Initial database searches returned 424 journal articles. The manual reference list search revealed one additional article. After removal of 176 duplicates, title and abstracting screening excluded 185 articles. Of the 64 articles that were screened at full text, six met the inclusion criteria.

\section{Study and participant characteristics}

Characteristics, strengths and limitations of the included studies are detailed in Table 2. Included studies involved participants recruited from specialist burns centres or outpatient rehabilitation sites in Canada, Sweden and Australia (Johnson et al., 2016; Mansfield et al., 2014; Nguyen et al., 2016; StergiouKita et al., 2014). Very specific patient populations limited the transferability of results to the wider burns population. A common strength among studies was relevant quotation usage to verify results.

\section{Figure 1}

Screening for Inclusion

Articles identified in manual search of references $(n=1)$

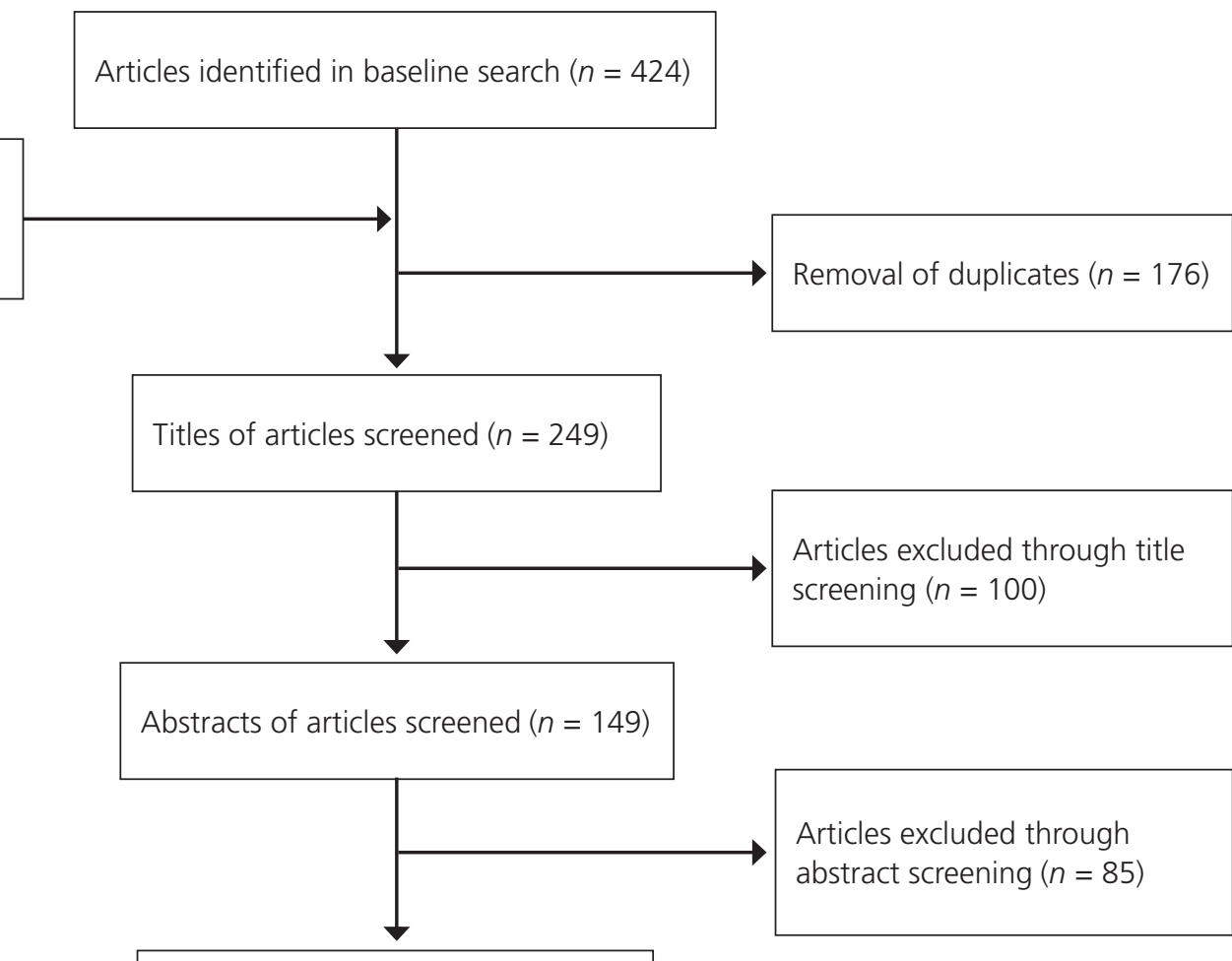

Potentially relevant articles retrieved for full text evaluation $(n=64)$

\begin{tabular}{|l|l|l|}
\hline & $\begin{array}{l}\text { Articles excluded through full- } \\
\text { text screening }(n=58) \\
-\end{array}$ \\
- & Not in English $(n=3)$ \\
Outside publishing date \\
timeframe $(n=20)$ \\
Outcome not related to \\
support to return to work or \\
meaningful activity $(n=25)$ \\
- Wrong study design $(n=10)$
\end{tabular}

Articles included in review $(n=6)$ 
Table 2

Study Characteristics

\begin{tabular}{|c|c|c|c|c|}
\hline Author & $\begin{array}{l}\text { Methodology and } \\
\text { country }\end{array}$ & Aims & Participants & Strengths/limitations \\
\hline $\begin{array}{l}\text { Öster et al. } \\
(2010)\end{array}$ & $\begin{array}{l}\text { Qualitative } \\
\text { descriptive } \\
\text { (content analysis) } \\
\text { Sweden }\end{array}$ & $\begin{array}{l}\text { Exploration of burn } \\
\text { patients' perception } \\
\text { of factors seen as } \\
\text { facilitators or barriers } \\
\text { in the process of } \\
\text { returning to work after } \\
\text { a severe burn injury }\end{array}$ & $\begin{array}{l}n=39 \\
\text { Burn injury patients } \\
\text { previously } \\
\text { employed or } \\
\text { studying }\end{array}$ & $\begin{array}{l}\text { Strengths } \\
\text { Participants chose interview location } \\
\text { Neutral, experienced interviewer } \\
\text { Moderate sample size } \\
\text { Effective use of quotations to verify results } \\
\text { Limitations } \\
\text { Only included previously employed } \\
\text { participants } \\
\text { Participants interviewed up to six years after } \\
\text { RTW } \\
\text { Two participants interviewed together }\end{array}$ \\
\hline $\begin{array}{l}\text { Mansfield et } \\
\text { al. (2014) }\end{array}$ & $\begin{array}{l}\text { Qualitative } \\
\text { descriptive } \\
\text { (thematic } \\
\text { analysis) } \\
\text { Canada }\end{array}$ & $\begin{array}{l}\text { Assessment of how } \\
\text { worker, job, workplace, } \\
\text { injury, compensation, } \\
\text { and support elements } \\
\text { interact and influence } \\
\text { the RTW process }\end{array}$ & $\begin{array}{l}n=13 \\
\text { Burn survivors who } \\
\text { experienced } \\
\text { a workplace } \\
\text { electrical injury }\end{array}$ & $\begin{array}{l}\text { Strengths } \\
\text { Provides specialised insight into electrical } \\
\text { injuries } \\
\text { Detailed data analysis protocol } \\
\text { Effective use of quotations to verify results } \\
\text { Limitations } \\
\text { Small sample size } \\
\text { Specific type of burn injury } \\
\text { Impairment information was self-reported } \\
\text { Authors do not outline strengths and } \\
\text { limitations of the study }\end{array}$ \\
\hline $\begin{array}{l}\text { Stergiou- } \\
\text { Kita et al. } \\
(2014)\end{array}$ & $\begin{array}{l}\text { Qualitative } \\
\text { descriptive } \\
\text { (thematic } \\
\text { analysis) } \\
\text { Canada }\end{array}$ & $\begin{array}{l}\text { Aimed at gaining } \\
\text { an understanding } \\
\text { of workers' RTW } \\
\text { experiences including } \\
\text { challenges and } \\
\text { beneficial support }\end{array}$ & $\begin{array}{l}n=13 \\
\text { Burn survivors who } \\
\text { experienced } \\
\text { a workplace } \\
\text { electrical injury } \\
\text { and attempted to } \\
\text { RTW }\end{array}$ & $\begin{array}{l}\text { Strengths } \\
\text { Provides specialised insight into electrical } \\
\text { injuries } \\
\text { Detailed data analysis protocol } \\
\text { Effective use of quotations to verify results } \\
\text { Limitations } \\
\text { Small sample size } \\
\text { Specific type of burn injury } \\
\text { Impairment information was self-reported }\end{array}$ \\
\hline $\begin{array}{l}\text { Johnson et al. } \\
\text { (2016) }\end{array}$ & $\begin{array}{l}\text { Heideggerian } \\
\text { phenomenology } \\
\text { Australia }\end{array}$ & $\begin{array}{l}\text { Interprets information on } \\
\text { the lived experience } \\
\text { of hospitalisation and } \\
\text { recovery following burn } \\
\text { injury }\end{array}$ & $\begin{array}{l}n=18 \\
\text { Burn patients and } \\
\text { family members } \\
\text { following hospital } \\
\text { discharge }\end{array}$ & $\begin{array}{l}\text { Strengths } \\
\text { Perspectives from patients and carers } \\
\text { Effective use of quotations to verify results } \\
\text { Limitations } \\
\text { Only recruited from one state in Australia } \\
\text { Only included English speaking participants } \\
\text { High proportion of industrial accidents }\end{array}$ \\
\hline $\begin{array}{l}\text { Lamble et al. } \\
\text { (2019) }\end{array}$ & $\begin{array}{l}\text { Cross-sectional } \\
\text { study with } \\
\text { a qualitative } \\
\text { component } \\
\text { Canada }\end{array}$ & $\begin{array}{l}\text { Comparing RTW } \\
\text { outcomes between the } \\
\text { KT intervention group } \\
\text { and a control group, } \\
\text { describing the RTW } \\
\text { and the KT intervention } \\
\text { experience }\end{array}$ & $\begin{array}{l}n=29 \\
\text { Burn survivors } \\
\text { who participated } \\
\text { in the KT } \\
\text { intervention } \\
\text { study }(n=15) \\
\text { Matched controls } \\
(n=14)\end{array}$ & $\begin{array}{l}\text { Strengths } \\
\text { Included participants from multiple } \\
\text { employment fields } \\
\text { Groups matched for age, sex and TBSA } \\
\text { Both qualitative and quantitative } \\
\text { information } \\
\text { Clear validation process of questionnaires } \\
\text { Limitations } \\
\text { Groups not matched by job task, burn } \\
\text { location or time since injury } \\
\text { Excluded those who had not returned to } \\
\text { work } \\
\text { Interviewed up to two years following } \\
\text { intervention }\end{array}$ \\
\hline
\end{tabular}




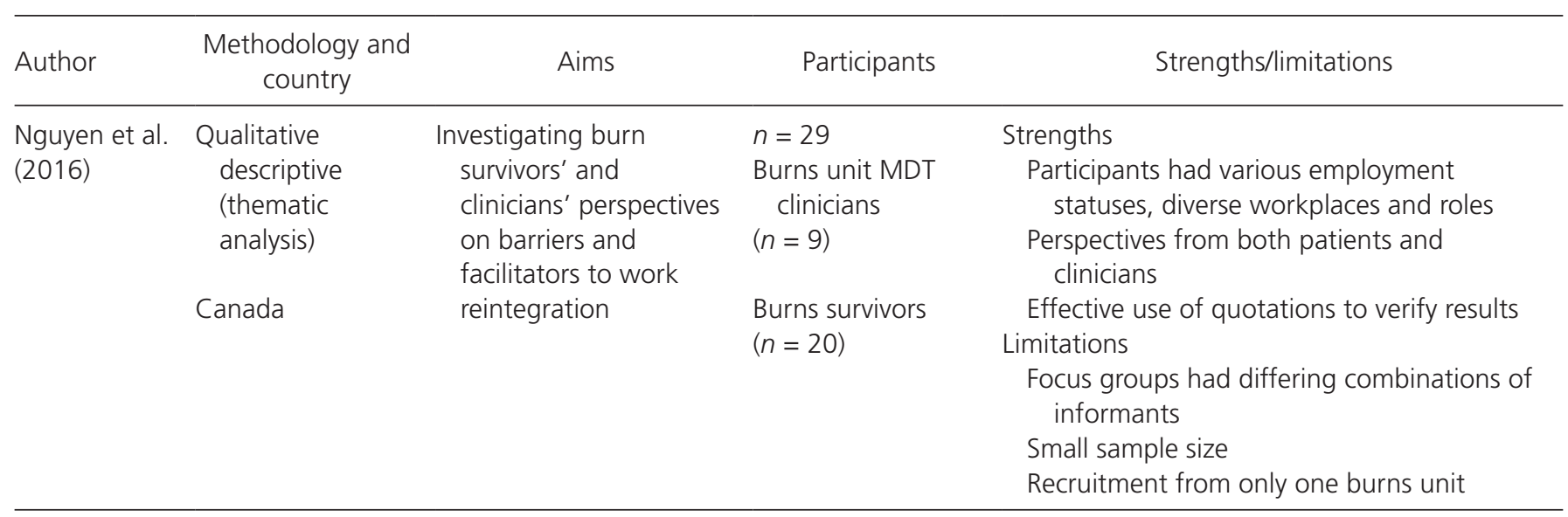

Note. $\mathrm{KT}=$ knowledge translation; MDT = multidisciplinary team; RTW = return to work; TBSA = total body surface area.

The six qualitative studies reported on 141 participants, with sample sizes ranging from 13 to 39 (Johnson et al., 2016; Lamble et al., 2019; Mansfield et al., 2014; Nguyen et al., 2016; Öster et al., 2010; Stergiou-Kita et al., 2014). All studies included adults between the ages of 20 and 59 years and the majority (80\%) of participants were male. Between $24 \%$ and $100 \%$ of burn injuries were work-related. The mean percentage total burn surface area (TBSA) of burn injuries was recorded by Johnson and colleagues (2016), Lamble and colleagues (2019), and Öster and colleagues (2010) and ranged from 14.3\% to $29 \%$. Five studies reported time since injury, which ranged from two months to over 10 years (Lamble et al., 2019; Mansfield et al., 2014; Nguyen et al., 2016; Öster et al., 2010; StergiouKita et al., 2014). These studies also reported the percentage of participants who returned to work as ranging from $65 \%$ to $85 \%$. Participants returned to various employment fields in differing capacities as outlined in Table 3.

Study quality

All six studies were considered high quality and were included (Public Health Resource Unit, 2002). In Section A, five studies scored 'Yes' for five of the six questions corresponding to high validity of results (Johnson et al., 2016; Lamble et al., 2019; Mansfield et al., 2014; Nguyen et al., 2016; Stergiou-Kita et al., 2014). The only weakness was lack of consideration of the researcher-participant relationship. The exception was Öster et al. (2011), who employed a neutral interviewer to minimise the influence of pre-existing assumptions during interviews, therefore scoring 'Yes' for all six questions. All six studies scored 'Yes' to all six questions in Section B, corresponding to appropriate reporting of results. In Section C, all included studies were determined to be valuable, therefore having high external validity.

Thematic synthesis

Five analytic themes were identified through thematic synthesis: 1) Addressing the complex impact of burn injury; 2) personal connections as vital support; 3) skilled and specialised healthcare as central to RTW; 4) value of knowledge; and 5) considering the work environment. Each theme contained several sub-themes, which are outlined in Figure 2. While Figure
2 displays all synthesised data, the following results outline key information relevant to burn injury support only. Excluded data did not describe factors specific to support to RTW, such as barriers to RTW or encompassed information less relevant to burns support clinicians such as union or financial supports. Note that the themes described below are analytic themes that were developed as the next step on from descriptive themes, in order to specifically address the need for key clinical information. We have comprehensively referenced the original studies that contributed data to each aspect, but have not included specific quotes. The themes are constructed across multiple studies, and multiple points of references within those studies, and the nature of analytic themes is that they aim to "go beyond" (Thomas \& Harden, 2008, p. 7) the findings of the primary studies - key to the original contribution of a synthesis such as this.

\section{Theme 1: Addressing the complex impact of burn injury}

1.1. Potential for complex impairments. Burn injuries resulted in various physical, cognitive and psychosocial impairments leading to functional limitations and difficulty performing work tasks (Lamble et al., 2019; Mansfield et al., 2014; Nguyen et al., 2016). Recovery timeframes, and therefore RTW, varied depending on the nature and degree of the injury and resulting impairments. Some physical impairments may be short-term, such as muscle weakness, while others, like muscle contractures, remained long after discharge, significantly inhibiting RTW for study participants (Mansfield et al., 2014; Öster et al., 2010; Stergiou-Kita et al., 2014). Recovery from less-visible psychological challenges, such as post-traumatic stress disorder (PTSD), was reported to take longer than recovery from physical impairments (Johnson et al., 2016).

The impact of different types of burn injuries also varied. Electrical burn injuries may cause invisible, severe, persistent impairments with additional cognitive challenges such concentration and memory issues that further complicate recovery (Mansfield et al., 2014; Stergiou-Kita et al., 2014). Impairments needed to be considered at an individual level, which meant that RTW could not be a standardised process or timeframe. 


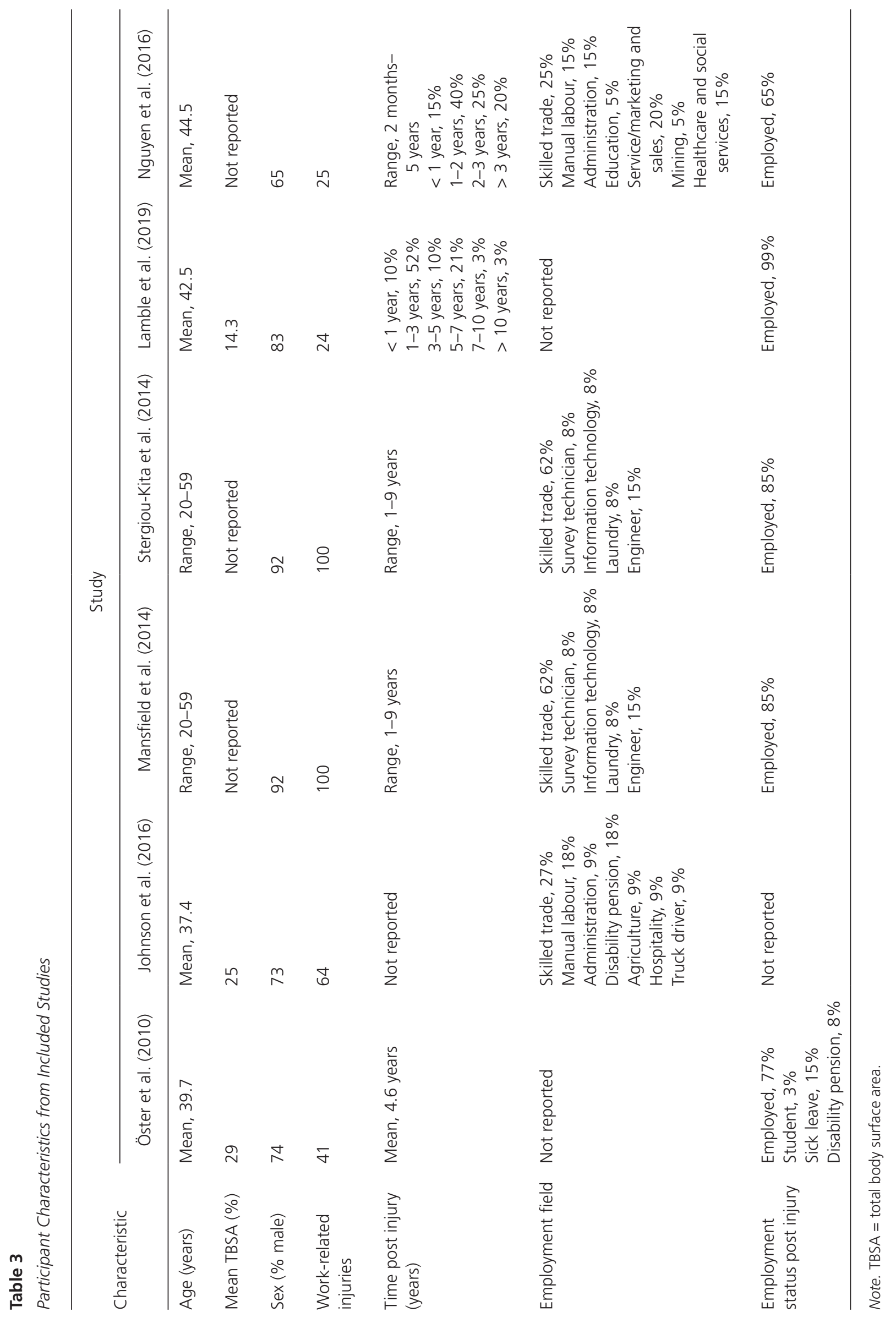


Figure 2

Themes from Thematic Synthesis

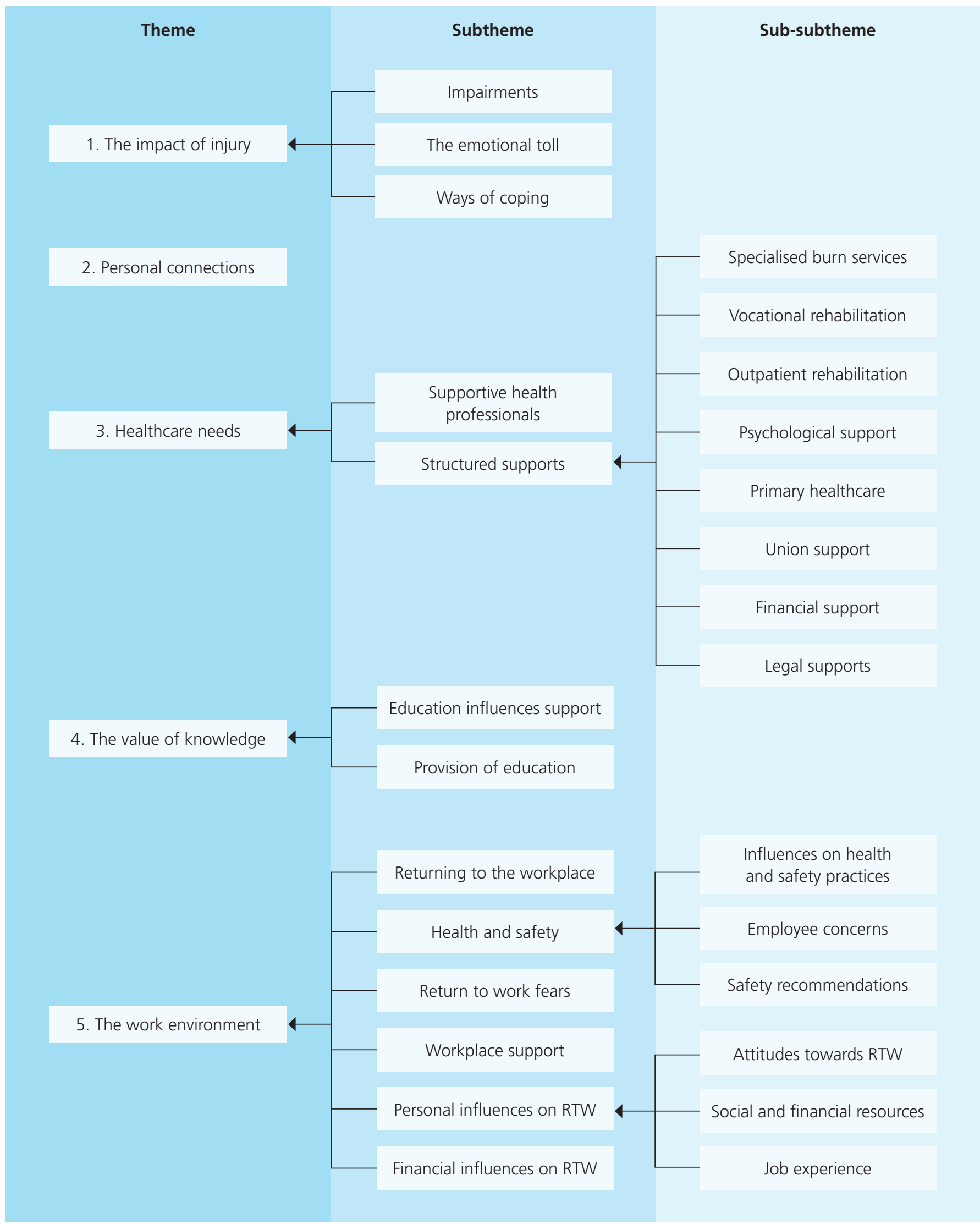

Note. RTW = return to work. 
1.2. Emotional toll. Emotional trauma experienced by some people with burn injury worsened RTW stress (Johnson et al., 2016; Lamble et al., 2019). Emotional challenges included feelings of dejection, fear, frustration and appearance-related self-consciousness (Johnson et al., 2016; Lamble et al., 2019). Questions about the injury or changes in appearance reminded people of their accident, causing added discomfort (Lamble et al., 2019). It was important that others supporting people who had experienced burn injury considered the added emotional impact of injury. Burn injury may cause identity challenges as people lose a degree of control over their lives after injury (Johnson et al., 2016). Specifically, job changes could elicit occupational grieving due to the relationship between career and identity (Nguyen et al., 2016). Identity challenges linked to career changes add to the emotional toll of injury, inhibiting RTW (Nguyen et al., 2016)

1.3. Supporting coping. Support to facilitate RTW often involved more wide-ranging support for people to cope with emotional trauma, fears and identity concerns. People with burn injury experiencing emotional trauma appreciated psychological assistance and additional time to reflect and process injury events (Johnson et al., 2016; Lamble et al., 2019; Stergiou-Kita et al., 2014). Practical solutions like involvement in self-care and finding novel ways of completing tasks were experienced to further enhance recovery through facilitation of independence (Johnson et al., 2016; Öster et al., 2010).

People with burn injury needed to confront re-injury fears as a way of coping with lasting emotional trauma, especially following workplace accidents (Öster et al., 2010). Returning to the injury-site was one way of confronting and overcoming one's fears (Nguyen et al., 2016). Effective coping strategies can help people with burn injury to manage emotional stressors throughout the RTW journey.

Theme 2: Personal connections as vital support Relationships with compassionate and understanding family members, friends, employers, colleagues and other people with burn injury were reported to provide crucial informal support (Johnson et al., 2016; Lamble et al., 2019; Mansfield et al., 2014; Nguyen et al., 2016; Öster et al., 2010; Stergiou-Kita et al., 2014). Informal support networks provided comfort, distraction, motivation and practical assistance, which facilitated RTW (Johnson et al., 2016; Lamble et al., 2019; Mansfield et al., 2014; Öster et al., 2010).

Theme 3: Skilled and specialised healthcare as central to RTW

3.1. Supportive, skilled health professionals. Supportive, motivating and emotionally invested health professionals were experienced as facilitators of RTW (Lamble et al., 2019; Mansfield et al., 2014; Öster et al., 2010). There were multiple elements to this experience: healthcare providers needed to recognise each person's unique injury and refer those experiencing ongoing symptoms for further treatment (StergiouKita et al., 2014). Studies also indicated that health professionals should advocate for their patients while also providing selfadvocacy strategies (Mansfield et al., 2014; Stergiou-Kita et al., 2014). Self-advocacy skills could empower people with burn injury to take greater control of their rehabilitation and have the confidence to request further support if required (StergiouKita et al., 2014). This facilitates people to take charge of their recovery journey, working towards RTW.

\subsection{Structured supports that recognise vocational needs}

Specialised burn services. Specialised services with expert healthcare professionals were seen to provide the most appropriate care following burn injury, improving RTW outcomes (Mansfield et al., 2014; Stergiou-Kita et al., 2014).

Deliberate, structured vocational rehabilitation. Structured VR facilitated RTW through job-task analysis, expert workadaptation recommendations and work-readiness assessments (Lamble et al., 2019; Öster et al., 2010; Stergiou-Kita et al., 2014). Establishing work-readiness was considered an essential part of VR and the RTW process, indicating that comprehensive, burn-injury-specific resources for assessing and addressing workreadiness are needed to enable successful RTW (Öster et al., 2010).

VR that was reported to be successful facilitated effective communication between the person with burn injury, their family, workplace and healthcare team (Lamble et al., 2019; Mansfield et al., 2014; Nguyen et al., 2016; Öster et al., 2010; Stergiou-Kita et al., 2014). A comprehensive VR MDT was considered vital, including VR coordinators who can problemsolve VR issues from the initial injury to RTW (Öster et al., 2010). Co-ordinated VR can enable a smoother RTW transition. Synthesised, the qualitative evidence indicated that early engagement in vocational conversations is beneficial, which can begin with the acute MDT and carry on into the community setting.

\section{Participation-focused outpatient rehabilitation. Early} rehabilitation was considered necessary to help people with burn injury regain adequate function required for activities of both daily living and work tasks. Helpful post-discharge physiotherapy rehabilitation involved task-related strength and endurance training (Lamble et al., 2019; Öster et al., 2010). Individualised training and goal setting was reported to elicit functional improvements, which facilitated RTW (Lamble et al., 2019; Öster et al., 2010). Shifting the focus from impairments to activities and participation during rehabilitation optimised subjective quality of life in the longer term (Lamble et al., 2019).

Psychological support. Formal psychological support was recommended, with studies indicating it should be offered to all people with burn injury through routine, early initiation of psychological screening and referrals (Johnson et al., 2016; Lamble et al., 2019; Öster et al., 2010; Stergiou-Kita et al., 2014). As illustrated in prior themes, people with burn injury often experience psychological challenges; therefore, appropriate psychological support is necessary to facilitate recovery and RTW.

Theme 4: The value of knowledge

4.1. Education influences support. People with burn injury were reported to feel better supported by those with burn injury knowledge (Lamble et al., 2019; Nguyen et al., 2016; Öster et al., 2010; Stergiou-Kita et al., 2014). People with burn injury could more effectively communicate their needs when others understood their injury experience (Lamble et al., 2019; Nguyen 
et al., 2016). Appropriate education enabled people with burn injury to RTW with reduced anxiety about workplace interactions (Lamble et al., 2019). Examples of beneficial education included describing a major burn injury, the pressure garments and adaptive equipment used to treat scars, and the rehabilitation process (Lamble et al., 2019). Uninformed employers were felt to be more likely to pressure people to prematurely return to previous tasks (Lamble et al., 2019; Nguyen et al., 2016; Öster et al., 2010; Stergiou-Kita et al., 2014). In particular, electrical injuries are often misunderstood and not legitimised by employers, work colleagues and insurance providers due to the invisible sequalae of injury (Mansfield et al., 2014; Stergiou-Kita et al., 2014). Therefore, specific information should be provided to improve support received.

4.2. Provision of education. Studies supported the provision of education to the person with burn injury, their workplace and family and friends using a flexible, personalised and accessible information tool (Lamble et al., 2019; Nguyen et al., 2016). Education about the roles of various health professionals helped people with burn injury to better direct their RTW queries (Lamble et al., 2019). Explaining the healing and rehabilitation process provided people with burn injury with the knowledge and terminology to discuss their condition (Lamble et al., 2019). Provision of additional social interaction strategies assists with workplace reintegration (Nguyen et al., 2016).

Workplace education about possible physical impairments should include solutions to overcome these barriers (Mansfield et al., 2014; Nguyen et al., 2016). Inclusion of testimonies of previous burn injury RTW successes may be useful (Mansfield et al., 2014; Nguyen et al., 2016). Informative workplace conversations facilitate increased understanding of the worker's journey and their needs, and help to justify required accommodations (Mansfield et al., 2014; Nguyen et al., 2016).

\section{Theme 5: Considering the work environment}

5.1. Benefits of returning to the workplace. As well as practical issues such as financial needs, is important to consider the therapeutic benefits of returning to work (Johnson et al., 2016; Lamble et al., 2019; Nguyen et al., 2016). Working was reported to elicit improvements in both function and self-esteem while providing structure and routine (Lamble et al., 2019; Nguyen et al., 2016; Öster et al., 2010).

\subsection{RTW Fears. The RTW process may create fear and} anxiety among people with burn injury, where they experience an enduring sense of vulnerability due to re-injury or unemployment fears (Johnson et al., 2016; Lamble et al., 2019; Mansfield et al., 2014; Stergiou-Kita et al., 2014). This could further impede RTW. Work-related injuries have been correlated with increased RTW stress; therefore, people returning to work after burn injury may require increased emotional support (Johnson et al., 2016; Stergiou-Kita et al., 2014). Furthermore, while initiating VR was considered appropriate quite early in the rehabilitation process, the timing of RTW was discussed as an important issue to be carefully considered. Sometimes the timing of RTW could create added stress, as people with burn injury experienced pressure to RTW before they were ready (Lamble et al., 2019; Stergiou-Kita et al., 2014). Premature RTW can cause added job-performance anxiety and fear of losing one's professional reputation, while also triggering symptoms of PTSD (Lamble et al., 2019; Stergiou-Kita et al., 2014).

5.3. Workplace support. RTW was facilitated when people with burn injury returned to supportive work environments with task modifications and assistance from colleagues (Lamble et al., 2019; Mansfield et al., 2014; Nguyen et al., 2016; Öster et al., 2010). Flexible, progressive RTW enabled people with burn injury to engage in rehabilitation while maintaining employment, further facilitating work reintegration (Johnson et al., 2016; Lamble et al., 2019; Mansfield et al., 2014; Nguyen et al., 2016; Öster et al., 2010).

\section{DISCUSSION}

Theme one in this review has highlighted the emotional impact of burn injury and its effect on RTW. Perceived outcome following burn injury comprises both physical impairments and the psychosocial impact of injury (Kildal et al., 2005). Fear of re-injury was highlighted in the present review as a catalyst for anxiety and the potential to delay RTW. This fear has been reported to be one of the strongest predictors of delayed RTW (Bunzli et al., 2017). Emotional support has been highlighted within burns literature as an effective coping strategy (Kildal et al., 2005). Furthermore, the psychosocial benefits of RTW in itself are well described in VR literature (Bunzli et al., 2017). The present review supports informal support from family, friends, employers, colleagues and other people with burn injury who likely provide this crucial emotional support. The therapeutic benefits of returning to work were also highlighted in the present review.

Theme three identified a need for formal psychological intervention following burn injury due to the psychological and emotional impact of injury. Literature has shown the benefits of psychological treatment on symptoms, clinical outcomes and quality of life (Waddell et al., 2008). Finnes and colleagues (2019) evaluated the effect of psychological treatment on sickness absence among individuals with common mental or musculoskeletal disorders. The authors identified a reduction in sickness absence; however, specific effective treatment modalities were not identified (Finnes et al., 2019). As stress disorders and depression are prevalent following burn injury, formal psychological support for people with burn injury could be equally successful in reducing RTW time (Dalal et al., 2010).

This review outlined the importance of specialised, structured VR that includes work environment and/or job accommodation and effective communication between the workplace, the injured person and healthcare providers. Research with musculoskeletal and chronic condition populations supports structured VR programmes, improved communication and work adaptations (Franche et al., 2005; Waddell et al., 2008; Welsh Assembly Government, 2006). Temporary work accommodations facilitate early return to appropriate tasks, allowing for a gradual transition to previous work demands (Waddell et al., 2008). Additionally, as no single service can deliver effective VR alone, increased communication between RTW parties provides workers with more successful, coordinated care (Waddell et al., 2008). 
VR components are discussed extensively in literature, particularly within chronic condition populations (de Buck et al., 2002; Waddell et al., 2008; Welsh Assembly Government, 2006). Effective components include physical training, skills training, employment placement, personalised education and action plans, counselling, guidance and group meetings involving education, exercise and peer support (de Buck et al., 2002; Waddell et al., 2008; Welsh Assembly Government, 2006). Outpatient follow-up was highlighted in this review as an appropriate setting to deliver these key components. In the New Zealand setting, specialist VR providers may also be involved. RTW support for people with burn injury should consider inclusion of these elements, and clear communication between the various rehabilitation providers even when there is specialist VR provision, as research has highlighted the importance of coordinated care.

The value of knowledge and therefore the importance of appropriate education was another prevalent finding identified in theme four. Lamble and colleagues (2019) offered a possible method of delivering education. In this study, participants viewed six videos addressing various aspects of burn injuries, the recovery process and RTW. The participants then had the opportunity to show these videos to family, friends, employers and colleagues. An occupational therapist was also available to answer questions and discuss appropriate work tasks and potential adaptations (Lamble et al., 2019). While Lamble and colleagues' (2019) quantitative results were not significant, participants in this study identified the need for workplace education to enable progressive, safe RTW. Education remains a key component of successful VR among a variety of non-burn injury populations (Waddell et al., 2008). As public knowledge of burn injury rehabilitation is limited, workplaces are often not prepared for workers' specific needs in regard to job-task modifications, rehabilitation engagement and progressive RTW. Our review findings confirm that educated workplaces are experienced as more supportive during RTW. Additionally, people with burn injury who are educated are more likely to self-advocate (Lamble et al., 2019; Mansfield et al., 2014). Therefore, comprehensive education should be provided to all stakeholders.

This review identified that people with burn injury require a wealth of formal and informal support that facilitate RTW, outlined in themes two and four. Similarities can be seen in RTW literature in other injury populations. For example, Murphy and O'Hare (2011) found workplace-based social support as key in facilitating RTW after spinal cord injury. Workplace social support provides a welcoming environment, enhancing comfort and motivation (Murphy \& O'Hare, 2011). Health professionals should ensure people with burn injury receive adequate social support, either within or outside the workplace, and consider facilitating peer-support groups as part of VR (Grieve et al., 2020)

\section{Review strengths and limitations}

A key strength of this review was the rigour of the process, including independent screening and critique of all articles. Other strengths included following a pre-established process that outlined inclusion and exclusion criteria and analysis approach, and that we included recently published studies, ensuring relevance to the current system and climate.
The review was limited by lack of available research within the burn injury population. Authors were unable to address the return to meaningful activity aspect of the research question, due to absence of literature. The findings could also be limited by the search parameters. A limited number of databases were searched, and it is possible some key studies were not indexed in the selected databases. Finally, because we elected to resolve differences in reviewer decisions by discussion processes and all differences were quickly resolved in this way, we do not have data on initial inter-rater agreement.

A major limitation in application of the review findings to the local context was that no New Zealand burn injury studies were identified for inclusion. Furthermore, most participants were Caucasian, with very few Indigenous participants. As Māori are overrepresented in New Zealand burn statistics, it is important to examine the specific considerations required when supporting this population to RTW following burn injury (Tracy et al., 2019). Lack of Indigenous participants and methodologies makes it even more important to have further development in partnership with Māori as part of implementation of the recommendations from overseas research within an Aotearoa New Zealand context.

\section{Clinical implications}

Physiotherapists involved with burn injury rehabilitation should consider all aspects of this review to better understand the experiences and specialised needs of people who have experienced burn injury. Key clinical implications include referrals from the acute hospital setting to ensure early outpatient follow-up and provision of specialised VR and comprehensive education. Physiotherapists should consider referrals to ACC VR programmes alongside providing outpatient follow-up. Additionally, physiotherapists need to be aware of the importance of psychology input, ensuring appropriate referrals are made and psychology input is provided. Outpatient rehabilitation should include personalised, task-specific training. As part of the VR MDT, specialist physiotherapists must provide work adaptation recommendations and contribute to workreadiness training and assessment. Physiotherapists should provide detailed burn injury and RTW education to patients as well as workplace education as a part of VR. Physiotherapists as part of the VR MDT need to provide co-ordinated VR including effective communication between VR clinicians and the workplace.

\section{Recommendations for future research}

This review highlighted the lack of research addressing RTW support within the burn injury population. The importance of education was evident; however, an effective, standardised delivery tool still requires development. Building upon the findings of Lamble and colleagues (2019), future research should look to develop this tool with appropriate burn injury and RTW content discussed in the present review, considering video as an effective modality. Future research could assess current support provided by New Zealand burns units by gaining the perspectives of specialised health professionals and ACC representatives. This research should address considerations for Māori with burn injury. 


\section{CONCLUSION}

The present review has highlighted the complex nature of burn injury recovery with impairments that are not only physical but also psychological and emotional. Despite common RTW fears, RTW should be encouraged due to clear therapeutic benefits. Successful RTW should involve support from specialised, supportive health professionals through facilitation of structured VR, communication and collaboration between all involved parties, outpatient rehabilitation, workplace support, psychological support, comprehensive education and informal social support. Support that facilitates return to meaningful activity following burn injury remains unclear.

\section{KEY POINTS}

1. Both physical impairment and emotional trauma affect work-ability and return to work (RTW) after burn injury.

2. Knowledge of common experiences regarding impact of injury can assist clinicians, employers and people experiencing injury to facilitate a successful RTW.

3. Vocational rehabilitation after burn injury needs to be specialised to the burn injury experience while acknowledging core principles of vocational rehabilitation more generally.

4. Vocational rehabilitation intervention should span burn care settings from acute to community, making physiotherapists vital personnel when it comes to both support and education.

\section{DISCLOSURES}

No funding was received for the research. There are no conflicts of interest that may be perceived to interfere with or bias this study.

\section{PERMISSIONS}

No permissions were required.

\section{ADDRESS FOR CORRESPONDENCE}

Dr. Joanna Fadyl, Centre for Person Centred Research, Auckland University of Technology, Auckland, New Zealand.

Email: joanna.fadyl@aut.ac.nz

\section{REFERENCES}

Accident Compensation Corporation. (2016). Service schedule for outpatient burns treatment and burns scar management service. https://www.acc. co.nz/assets/contracts/outpatient-burn-scar-schedule.pdf

Bunzli, S., Singh, N., Mazza, D., Collie, A., Kosny, A., Ruseckaite, R., \& Brijnath, B. (2017). Fear of (re)injury and return to work following compensable injury: Qualitative insights from key stakeholders in Victoria, Australia. BMC Public Health, 17, 313. https://doi.org/10.1186/s12889017-4226-7

Counties Manukau Health. (2021). Auckland regional burn service/National burn service. https://www.healthpoint.co.nz/public/burns/aucklandregional-burn-service-national-burn

Dalal, P. K., Saha, R., \& Agarwal, M. (2010). Psychiatric aspects of burn. Indian Journal of Plastic Surgery, 43, S136-142. de Buck, P. D., Schoones, J. W., Allaire, S. H., \& Vliet Vlieland, T. P. (2002). Vocational rehabilitation in patients with chronic rheumatic diseases: A systematic literature review. Seminars in Arthritis and Rheumatism, 32(3), 196-203. https://doi.org/10.1053/sarh.2002.34609

Escorpizo, R., Reneman, M. F., Ekholm, J., Fritz, J., Krupa, T., Marnetoft, S.-U., Maroun, C. E., Guzman J. R., Suzuki, Y., Stucki, G., \& Chan, C. C. (2011) A conceptual definition of vocational rehabilitation based on the ICF: Building a shared global model. Journal of Occupational Rehabilitation, 21(2), 126-133. https://doi.org/10.1007/s10926-011-9292-6

Espinoza, L. F., Simko, L. C., Goldstein, R., McMullen, K. A., Slocum, C., Silver, J. K., Herndon, D. N., Suman, O. E., Meyer, W. J., Gibran, N. S. Kowalske, K., Zafonte, R., Ryan, C. M. \& Schneider, J. C. (2019). Postacute care setting is associated with employment after burn injury. Archives of Physical Medicine and Rehabilitation, 100(11), 2015-2021. https://doi. org/10.1016/j.apmr.2019.06.007

Esselman, P. C. (2011). Community integration outcome after burn injury. Physical Medicine and Rehabilitation Clinics, 22(2), 351-356. https://doi. org/10.1016/j.pmr.2011.01.001

Finnes, A., Enebrink, P., Ghaderi, A., Dahl, J., Nager, A., \& Öst, L. G. (2019) Psychological treatments for return to work in individuals on sickness absence due to common mental disorders or musculoskeletal disorders: A systematic review and meta-analysis of randomized-controlled trials. International Archives of Occupational and Environmental Health, 92(3), 273-293. https://doi.org/10.1007/s00420-018-1380-x

Flemming, K., Booth, A., Garside, R., Tunçalp, Ö., \& Noyes, J. (2019). Qualitative evidence synthesis for complex interventions and guideline development: Clarification of the purpose, designs and relevant methods BMJ Global Health, 4(Suppl. 1), e000882. https://doi.org/10.1136/ bmjgh-2018-000882

Franche, R.-L., Cullen, K., Clarke, J., Irvin, E., Sinclair, S., \& Frank, J.; Institute for Work \& Health (IWH) Workplace-Based RTW Intervention Literature Review Research Team. (2005). Workplace-based return-to-work interventions: A systematic review of the quantitative literature. Journal of Occupational Rehabilitation, 15(4), 607-631. https://doi.org/10.1007/ s10926-005-8038-8

Gobelet, C., Luthi, F., Al-Khodairy, A. T., \& Chamberlain, M. A. (2007). Vocational rehabilitation: A multidisciplinary intervention. Disability \& Rehabilitation, 29(17), 1405-1410. https://doi. org/10.1080/09638280701315060

Grieve, B., Shapiro, G. D., Wibbenmeyer, L., Acton, A., Lee, A., Marino, M. Jette, A., Schneider, J. C., Kazis, L. E., \& Ryan, C. M.; The LIBRE Advisory Board. (2020). Long-term social reintegration outcomes for burn survivors with and without peer support attendance: A Life Impact Burn Recovery Evaluation (LIBRE) study. Archives of Physical Medicine and Rehabilitation, 101(1), S92-S98. https://doi.org/10.1016/j.apmr.2017.10.007

Higgins, J. P. T., Thomas, J., Chandler, J., Cumpston, M., Li, T., Page, M., \& Welch, V. (Eds.). (2019). Cochrane handbook for systematic reviews of interventions version 6.0 (updated July 2019). The Cochrane Collaboration. Available from handbook.cochrane.org.

Johnson, R. A., Taggart, S. B., \& Gullick, J. G. (2016). Emerging from the trauma bubble: Redefining 'normal' after burn injury. Burns, 42(6), 12231232. https://doi.org/10.1016/j.burns.2016.03.016

Kildal, M., Willebrand, M., Andersson, G., Gerdin, B., \& Ekselius, L. (2005). Coping strategies, injury characteristics and long-term outcome after burn injury. Injury, 36(4), 511-518. https://doi.org/10.1016/j.injury.2004.06.013

Lamble, M., Seto, V., Ye, Z., Couture, C., de Oliveira, A., Calva, V., Couture, M.-A., Poulin, C., LaSalle, L., \& Nedelec, B. (2019). Perceived value of a knowledge translation intervention designed to facilitate burn survivors' work reintegration. Journal of Burn Care \& Research, 40(6), 846-856. https://doi.org/10.1093/jbcr/irz100

Levack, W. M. M. (2012). The role of qualitative metasynthesis in evidencebased physical therapy. Physical Therapy Reviews, 17(6), 390-397. https:// doi.org/10.1179/1743288X12Y.0000000020 
Mansfield, E., Stergiou-Kita, M., Kirsh, B., \& Colantonio, A. (2014). After the storm: The social relations of return to work following electrical injury. Qualitative Health Research, 24(9), 1183-1197. https://doi. org/10.1177/1049732314545887

Mason, S. T., Esselman, P., Fraser, R., Schomer, K., Truitt, A., \& Johnson, K. (2012). Return to work after burn injury: A systematic review. Journal of Burn Care \& Research, 33(1), 101-109. https://doi.org/10.1097/ BCR.0b013e3182374439

Murphy, G., \& O'Hare, M. (2011). The role of workplace social support in disability management. In H. G. Harder \& T. Geisen (Eds.), Disability management and workplace integration: International research findings (pp. 43-58). Routledge.

Nguyen, N. T., Lorrain, M., Pognon-Hanna, J. N., Elfassy, C., Calva, V., de Oliveira, A., \& Nedelec, B. (2016). Barriers and facilitators to work reintegration and burn survivors' perspectives on educating work colleagues. Burns, 42(7), 1477-1486. https://doi.org/10.1016/j. burns.2016.05.014

Öster, C., Kildal, M., \& Ekselius, L. (2010). Return to work after burn injury: Burn-injured individuals' perception of barriers and facilitators. Journal of Burn Care \& Research, 31(4), 540-550. https://doi.org/10.1097/ BCR.0b013e3181e4d692

Ouzzani, M., Hammady, H., Fedorowicz, Z., \& Elmagarmid, A. (2016). Rayyan - a web and mobile app for systematic reviews. Systematic Reviews, 5 , 210. https://doi.org/10.1186/s13643-016-0384-4

Public Health Resource Unit. (2002). Critical Appraisal Skills Programme: Making sense of evidence. https://casp-uk.net/

Quinn, T., Wasiak, J., \& Cleland, H. (2010). An examination of factors that affect return to work following burns: A systematic review of the literature. Burns, 36(7), 1021-1026. https://doi.org/10.1016/j. burns.2009.10.001
Stergiou-Kita, M., Mansfield, E., Bayley, M., Cassidy, J. D., Colantonio, A. Gomez, M., Jeschke, M., Kirsh, B., Kristman, V., Moody, J., \& Vartanian, O. (2014). Returning to work after electrical injuries: Workers' perspectives and advice to others. Journal of Burn Care \& Research, 35(6), 498-507. https://doi.org/10.1097/BCR.0000000000000041

Thomas, J., \& Harden, A. (2008). Methods for the thematic synthesis of qualitative research in systematic reviews. BMC Medical Research Methodology, 8, 45. https://doi.org/10.1186/1471-2288-8-45

Tracy, L. M., McInnes, J., Gong, J., Karunakaran, R., \& Gabbe, B. (2019). Burns registry of Australia and New Zealand 9th annual report. Monash University. https://anzba.org.au/assets/BRANZ_AnnualReport_Year9_FINAL. $\mathrm{pd}$

Tracy, L. M., Rosenblum, S., \& Gabbe, B. J. (2020). Burns registry of Australia and New Zealand (BRANZ) 2018/19 annual report. Monash University. https://anzba.org.au/assets/360120-BRANZ-report18_19_FINAL.pdf

Waddell, G., Burton, A. K., \& Kendall, N. A. (2008). Vocational rehabilitation. What works, for whom, and when? https://assets. publishing.service.gov. uk/government/uploads/system/uploads/attachment_data/file/209474/ hwwb-vocational-rehabilitation.pdf

Welsh Assembly Government. (2006). Designed to improve health and the management of chronic conditions in Wales. An integrated model and framework. https://www.wales.nhs.uk/documents/Chronic_Conditions English.pdf

Wiechman, S. A., Carrougher, G. J., Esselman, P. C., Klein, M. B., Martinez, E. M., Engrav, L. H., \& Gibran, N. S. (2015). An expanded delivery model for outpatient burn rehabilitation. Journal of Burn Care \& Research, 36(1) 14-22. https://doi.org/10.1097/BCR.0000000000000153 